\title{
ANÁLISE DO USO DA TERRA NO MUNICÍPIO DE VIÇOSA-MG MEDIADO POR CLASSIFICAÇÕES SUPERVISIONADAS COM REDES NEURAIS ARTIFICIAIS E MAXVER
}

Michelle Milanez França ${ }^{1}$, Elpídio Inácio Fernandes Filho ${ }^{2}$ e Bruno Toribio de Lima Xavier $^{3}$

Artigo recebido em 27/06/2009 e aceito em 29/11/ 2009

\section{RESUMO}

A quantificação das classes de uso do solo, obtida pela classificação das imagens de satélite permite uma política racional de planejamento territorial, urbano e ambiental. As geotecnologias vêm sendo empregadas devido à rapidez e qualidade dos produtos gerados. A imagem do município de Viçosa, localizado na Zona da Mata de Minas Gerais, foi obtida gratuitamente na internet e foi produzida pelo satélite sino-brasileiro CBERS 2. Para a classificação supervisionada foi feito visita a campo com finalidade de reconhecimento da área e para coleta de amostras de treinamento e validação. Foi utilizado GPS para identificar feições e georreferenciar os pontos de coleta. Realizaram-se duas classificações. A primeira foi feita com Redes Neurais Artificiais - RNA - utilizando o simulador "Java Neural Network Simulator" (JavaNNS) com o algoritmo de aprendizado "backpropagation". E na segunda utilizou-se o Algoritmo de Máxima Verossimilhança (Maxver). Foi feito ainda um estudo comparativo sobre a influência das bandas espectrais para a classificação supervisionada pelos dois métodos de classificação. Os índices de exatidão global e kappa foram maiores para o classificador de RNA's. O teste de significância (Z) mostrou que as RNA's são estatisticamente superiores ao Maxver.

PALAVRAS-CHAVE: Classificação de Imagens, Redes Neurais Artificiais, Maxver.

\section{ABSCTRACT}

The quantification of the classes of land use, by classifying Satellite images allow a more rational planning territorial, urban and environmental. The geo been employed due to the speed and quality of products generated. The image of the municipality of Viçosa, located in the Zona da Mata de Minas Gerais, was obtained free on the Internet and was produced by the Sino-Brazilian satellite CBERS 2. For the supervised classification was made a field trip with purpose of recognition of the area and sample collection training and validation. GPS was used to identify features and georeferenced the collection points. There are two classifications. The first was made with artificial neural networks - RNA - using the simulator "Java Neural Network Simulator (JavaNNS) with the algorithm for learning "Backpropagation". The other supervised classification using the Algorithm for Maximum Likelihood (MAXVER). It also made a study comparison on the influence of spectral bands for classification monitored both by RNA as the Maxver. The indices of accuracy and overall kappa were higher for the classifier of RNA's. The test significance (Z), conducted to compare whether there was statistical difference between the two classifiers showed that RNA's are statistically above the Maxver.

KEY WORDS: Image Classification, Artificial Neural Network, Maxver.

\footnotetext{
${ }^{1}$ Mestranda em Solos e Nutrição de Plantas - Universidade Federal de Viçosa. Endereço: Rua Antônio Torres, 180/01, Ramos.Viçosa-MG. Cep: 36570-000.E-mail: milanezmichelle@gmail.com

${ }^{2}$ Professor Adjuntol Departamento de Solos - UFV

${ }^{3}$ Eng. Agrônomo. Doutorando em Solos e Nutrição de Plantas - UFV
} 


\section{INTRODUÇÃO}

As imagens provenientes de sensores são representações digitais de uma porção da superfície da terra. Uma imagem também pode ser vista como uma matriz de pontos (ou pixels) com $m$ linhas por $n$ colunas, onde o valor de cada elemento representa a magnitude do total de energia eletromagnética refletida ou emitida pela(s) área(s) visitada(s) pelo(s) sensor(es). Assim, pode-se aplicar uma gama variada de técnicas de processamento digital de imagens para as matrizes numéricas, (Mather, 1987).

O sensoriamento remoto, através de imagens orbitais, também é conhecido pelo baixo custo de seus produtos, quando comparado com tradicionais métodos fotogramétricos e topográficos. Outra vantagem apresentada por esta tecnologia é a frequiência com que cada região na superfície da terra é visitada (coberta), o que possibilita o monitoramento temporal de fenômenos e recursos naturais. Em adição, as novas gerações de satélites estão produzindo dados com alta resolução espacial, levando esta tecnologia a ser aplicada numa variedade de áreas do conhecimento e enfatizando a necessidade de formas automáticas para o processamento e análises de imagens, (França, 2007).
Há diferentes formas de extração dos dados obtidos de sensores, como nos métodos tradicionais, supervisionados e não supervisionados. $\mathrm{Na}$ classificação visual ou fotointerpretação da imagem, o analista interpreta a imagem de forma a agrupá-la em classes relevantes, reconhecendo padrões semelhantes. $\mathrm{Na}$ forma automatizada, realizada por programas de computador, este agrupamento pode ser feito mediante intervenção ou não do analista, havendo, portanto, dois tipos de classificação: supervisionada e não supervisionada, (França, 2007).

A classificação supervisionada exige parte do conhecimento a priori do tema a ser classificado enquanto que a classificação não supervisionada é realizada de maneira automatizada. Para o primeiro caso, muitas vezes são feitas visitas a campo ou são usadas informações secundárias confiáveis sobre o tema em estudo. Em seguida, torna-se necessário fazer a seleção de variáveis discriminantes, ou seja, escolher a melhor combinação de dados obtidos de sensores remotos, atributos de terreno e outras informações que possam ser consideradas relevantes para a classificação. Para tanto, são escolhidas amostras de treinamento, que são pontos no campo nos quais a classificação do tema em estudo é 
conhecida. As amostras de treinamento são usadas para treinar o software classificador de imagens. Após o treinamento é necessário fazer a validação da classificação e para isto novamente é importante obter dados de campo. Com a comparação entre a classe predita pelo classificador e o dado real de campo é possível determinar a exatidão da classificação que é expressa através dos índices de exatidão global e índice kappa . Desta maneira funcionam as redes neurais artificiais (RNA's) e a classificação estatística pelo algoritmo de máxima verossimilhança (Maxver), (Wasserman, 1989 e Haykin, 2001).

As RNA's consistem numa tecnologia que se originou de ciências como a informática, neurociência, estatística, matemática, física, dentre outras. Atuam como simuladores de comportamento inteligentes que se baseiam no funcionamento do cérebro humano. O conhecimento é adquirido e armazenado pela rede através do método de aprendizado, que se processa pelas conexões entre os neurônios, também conhecidos como sinapses. A rede é composta de uma camada de entrada onde as informações provenientes das variáveis discriminantes são apresentadas ao classificador; uma camada de saída na qual a rede informa a classificação obtida a partir de um conjunto de variáveis discriminantes e de um número variável de camadas intermediárias, denominadas camadas ocultas, onde o processo de aprendizagem da rede ocorre, (Schalkoff, 1992).

A arquitetura da rede consiste nas variáveis empregadas na classificação, como os dados de entrada, a camada oculta, onde ocorre a multiplicação dos pesos somáticos que originam a classificação, e a classe de saída. Os dados de entrada consistem no número de bandas espectrais que a classificação utiliza, precedido por um neurônio cada. O número de neurônios na camada oculta deve ser testado, pois ainda não existe metodologia padrão, se considerarmos que cada classificação utiliza parâmetros e atributos diferentes, como a imagem utilizada, o tamanho da área, as classes amostradas, as bandas espectrais utilizadas, e desta forma não é possível generalizá-las. E a classe de saída é acompanhada pelo número de neurônios equivalente ao número das classes amostradas. Este algoritmo atualiza os pesos da última camada de acordo com a regra delta e para as outras camadas irem propagando o erro da saída para a entrada, alterando assim os pesos de acordo com a influência destes na saída, (Novo, 1989, Moreira, 2003 e França, 2007). 
O Maxver é o método de classificação, que considera a ponderação das distâncias entre médias dos níveis digitais das classes, utilizando parâmetros estatísticos. Semelhante ao funcionamento das RNA's, deve ser fornecido ao sistema um conjunto de dados ou amostras que representam bem as classes de interesse para que o classificador tenha condições de definir um diagrama de dispersão em torno da média, bem como a distribuição das probabilidades dos pixels pertencerem ou não à determinada classe, (França, 2007).

O objetivo deste trabalho foi avaliar a eficácia dos dois classificadores supervisionados citados anteriormente de forma a obter melhores índices de exatidão kappa e overall. Outro objetivo importante foi avaliar se a incorporação do índice NDVI ajudou a discriminar melhor as classes de uso e cobertura.

\section{MATERIAIS E MÉTODOS}

As imagens foram adquiridas no catálogo online do INPE (Instituto Nacional de Pesquisas Espaciais) pelo sensor CBERS $2-$ CCD $1 \times 5$ de 08/07/2006, bandas 2, 4 e 3. Após o recebimento da imagem, ela foi processada no programa ENVI, (Esri, 1996) para fazer a composição RGB ( $\mathrm{R}$ - red; $\mathrm{G}$ - green e $\mathrm{B}-$ blue). A imagem passou pelo processo de georreferenciamento. Considerando a facilidade em visualizar rios nas imagens de satélite, optou-se pela obtenção dos pontos de controle a partir da hidrografia do município.

O MDE (Modelo Digital de Elevação) foi criado a partir dos temas hidrografia, curva de nível e limite da área de estudo. Estas feições foram utilizadas pelo interpolador TIN - Triangular Irregular Network. Os grids foram gerados pelo interpolador com resolução espacial de $10 \mathrm{~m}$. Da mesma forma, as classes de declividade (slope) foram geradas a partir deste modelo de elevação e com resolução espacial também de $10 \mathrm{~m}$.

Foram escolhidas cinco classes de uso e cobertura do solo para serem reconhecidas por ambos classificadores. Essas classes foram: área urbana, café, mata/capoeira, pastagem conservada e pastagem degradada.

Para iniciar o processo de classificação supervisionada, preparou-se um mapa de trabalho, contendo a imagem de satélite, o limite do município, as estradas e a hidrografia. Adotou-se escala de 1:50.000. Foram realizadas três visitas a campo para coletar amostras de treinamento e de validação dos classificadores.

Para as RNA's e o Maxver, as amostras de treinamento foram definidas como polígonos no software ArcView. 
Foram utilizadas informações sobre o uso do solo coletadas em campo com o auxílio do GPS. Os polígonos foram identificados com o nome da classe de uso e a cobertura a qual eles pertencem.

No software ENVI, foi processado o índice NDVI, sensível em captar a resposta espectral da vegetação, além de possuir alta reflectância na banda infravermelho próximo. O procedimento foi realizado com as bandas 3 e 4 da imagem CBERS.

Em seguida, as informações contidas no MDE, nas três bandas espectrais da imagem CBERS-2 e no índice NDVI foram mescladas numa única imagem e em seguida esta teve os valores dos níveis digitais de cinza reescalados para o intervalo de 0 a 1 , no software Erdas. Com isso, foram coletadas amostras para os classificadores, usando os polígonos das amostras de treinamento. Dentro de cada polígono foram extraídas todas as informações mescladas anteriormente e estes dados foram gravados em arquivos no formato texto.

Os arquivos texto foram importados em planilhas Excel, onde foram selecionadas 400 amostras para cada classe de uso e cobertura, tanto para o treinamento dos classificadores quanto para a posterior validação da classificação. $\mathrm{O}$ arquivo final foi salvo em formato texto com a extensão NOR. Foi utilizado o aplicativo Funcpow para transformar a tabela do Excel no formato de entrada de dados na rede, utilizada pelo software JavaNNS.

Utilizou-se o software JavaNNS para abrir o arquivo de treinamento gerado anteriormente. $\mathrm{Na}$ seqüência, foram estabelecidos parâmetros que permitiram o funcionamento da rede, como a escolha do algoritmo backpropagation, o número de ciclos de aprendizado do classificador, a iniciação aleatória dos coeficientes e a arquitetura da rede, dentre outros parâmetros.

Para o treinamento do classificador estatístico Maxver, foi usado o mesmo conjunto de dados utilizados no treinamento da rede neural. A classificação foi feita somente através do software Funcpow (Vieira, 2000).

\section{RESULTADOS E DISCUSSÃO}

A partir das matrizes de confusão, obtidas tanto para a classificação com RNA's quanto para o Maxver, foi observado uma confusão entre as classes de pastagem conservada, pastagem degrada e área urbana. A pastagem conservada e a degradada consistem no mesmo padrão de cobertura, porém a conservada é agronomicamente melhor em função de uma série de fatores e cuidados tomados 
pelo agricultor como o manejo agronômico ou zootécnico, o uso de insumos, que aparenta um aspecto estético melhor na paisagem, passando a apresentar pastos verdes, uniformes e vegetados. Já as pastagens degradadas geralmente estavam localizadas em pastos descuidados, próximo a estradas vicinais e apresentaram uma característica que faz com que o classificador confundisse alguns pixels com a classe de área urbana, que foi a presença de solo exposto.

Nas matrizes de confusão, a classe 1 foi representada pela área urbana, a classe 2 pelo café, a classe 3 pela mata/capoeira, a classe 4 para pastagem conservada e a classe 5 para pastagem degradada. Os melhores resultados na classificação supervisionada foram encontrados nas imagens que continham as bandas RGB mescladas com o índice NDVI. Como as bandas RGB consistiram no formato padrão da imagem, elas também foram analisadas isoladamente para comprovar o incremento que o índice NDVI trouxe à classificação. O MDE não alterou os valores da classificação quando comparados com o valor obtido somente com as bandas RGB, por isso as matrizes de confusão destes valores serão apenas comentadas.

Nas Tabelas 1 e 2 encontram-se as matrizes de confusão desenvolvidas a partir das RNA's e do Maxver respectivamente com um conjunto amostral de 400 pixels. $\mathrm{O}$ resultado expresso na matriz de confusão gerada pelas RNA's (Tabela 1) apresentou um menor número de confusão interna entre pixels por classe, embora numa primeira observação os resultados parecessem induzir que a classificação gerada com o Maxver (Tabela 2) apresentasse resultados mais significativos, uma vez que o seu kappa e overall foram mais altos que os expressos na Tabela 1. Porém, em termos de índices de exatidão, as RNA's apresentaram resultados mais significativos.

Nas matrizes de confusão abaixo, pode-se observar que com a utilização das RNA's, embora aparentemente apresentasse índices kappa ligeiramente menores que os apresentados pelo Maxver, houve uma menor confusão entre pixels internos por classe.

Uma hipótese plausível para esta ocorrência generalizada consistiu na utilização do algoritmo backpropagation pelas RNA's. Este algoritmo foi fundamentado no aprendizado por correção de erros. Ao oferecer os pixels de treinamento à rede, ela ajustou pesos de forma que conseguisse adaptar-se aos diferentes estímulos de entrada, ocorrendo a partir deste momento o seu aprendizado. 
Um fato interessante que pode ser observado no processamento das RNA's consistiu na apresentação de um gráfico contendo uma curva de erros. Esta curva generalizou a forma de atuação dos algoritmos, que funcionaram de forma a alcançar o menor valor de erro possível.

A Tabela 3 expressou o resultado da classificação processada com a composição RGB e o índice NDVI. Não houve confusão interna entre os pixels por classe, até mesmo nas classes que apresentaram padrão de resposta espectral semelhante, como as pastagens, podendo ser destacado o bom desempenho das classes de pastagem conservada (classe 4) e pastagem degradada (classe 5) com respectivamente 96,5 e $95,5 \%$ de acerto.

A Tabela 4 foi gerada com o mesmo conjunto de variáveis aleatórias que a classificação expressa anteriormente (Tabela 3), porém com o algoritmo estatístico de máxima verossimilhança Maxver para contrastar os resultados. Os índices de exatidão kappa e overall da Tabela 3 foram maiores que os da Tabela 4. A única classe que apresentou uma certa vantagem na proporção de pixels classificados foi a de mata/capoeira (classe 3), com 1,5\% a mais no acerto de pixels.

Foi feito também a incorporação do MDE à composição RGB e ao índice NDVI, mas os resultados obtidos para ambos classificadores não foram muito diferentes daqueles alcançados com a composição RGB. Para as RNA's obtevese kappa de 0.901 e overall de $92,1 \%$. Já para o Maxver obteve-se kappa de 0,899 e overall de $91,88 \%$.

Com relação às classes de declividade, os resultados também não variaram muito. $\mathrm{O}$ interesse inicial em relação a elas foi especialmente para a cultura do café, que estava localizado nas cotas superiores, mas como a produção cafeeira no município é fragmentada em pequenas propriedades esse dado não foi muito significativo na imagem como um todo. Para as RNA's obteve-se kappa de 0,899 e overall de $91,9 \%$.

E para finalizar as análises, foi feito uma união de todas as variáveis analisadas (composição RGB, índice NDVI, MDE e Slope. Mas esta classificação também não agregou valores significativos aos encontrados com a composição RGB e o índice NDVI. Com as RNA's o kappa obtido aqui foi de 0,909 e overall de $92,7 \%$ ao passo que para o Maxver o kappa foi de 0.902 e o overall de $92,2 \%$.

Foi feito uma representatividade da quantidade dos pixels classificados na imagem pela abrangência da área do município (Tabela 5 e Figura 1). As pastagens ocuparam grande proporção no município, seguido da classe de 
Mata/Capoeira. O café consistiu numa cultura perene de grande significância para os pequenos agricultores da região, uma vez que na zona da mata mineira esta cultura é amplamente empregada nas pequenas propriedades rurais. A classe de área urbana apresentou um tamanho reduzido em relação ao tamanho real, pois muitos de seus pixels foram alocados para as classes de pastagem degradada, fazendo com que esta classe aumentasse sua real proporção.

\section{CONCLUSÃO}

Pelas matrizes de confusão dos testes com os atributos mencionados acima, percebeu-se que o melhor desempenho da classificação em relação aos índices de exatidão foi processado com a composição RGB e com o índice NDVI. Os índices kappa e overall foram de 0,958 e de 96.6 respectivamente. Pôde ser notada menor confusão entre as classes anteriormente mensuradas como mais conflitantes. O NDVI de fato foi um bom separador entre os pixels de vegetação e até mesmo para com os pixels de pastagem, visto que a confusão entre suas subclasses não foram conflitantes.

A imagem CBERS foi significativa para separar classes distintas, porém, as classes em que houve similaridade na resposta espectral não foram bem distinguidas pelos classificadores. Há, portanto, necessidade de se empregar imagens com melhor resolução espacial para classes que apresentam resposta espectral semelhante. 
Tabela 1 - Matriz de confusão obtida pelo simulador e redes JavaNNS com a composição RGB

\begin{tabular}{cccccccc}
\hline Classe & $\mathbf{1}$ & $\mathbf{2}$ & $\mathbf{3}$ & $\mathbf{4}$ & $\mathbf{5}$ & Total & Usuário \\
\hline $\mathbf{1}$ & $\mathbf{3 5 9}$ & 1 & 0 & 9 & 27 & 396 & 90.7 \\
$\mathbf{2}$ & 0 & $\mathbf{3 9 8}$ & 1 & 0 & 0 & 399 & 99.7 \\
$\mathbf{3}$ & 0 & 0 & $\mathbf{3 9 9}$ & 1 & 0 & 400 & 99.8 \\
$\mathbf{4}$ & 16 & 0 & 0 & $\mathbf{3 4 8}$ & 56 & 420 & 82.9 \\
$\mathbf{5}$ & 25 & 1 & 0 & 42 & $\mathbf{3 1 7}$ & 385 & 82.3 \\
$\mathbf{U}$ & 0 & 0 & 0 & 0 & 0 & 0 & 0.0 \\
Total & 400 & 400 & 400 & 400 & 400 & 2000 & \\
Produtor & 89.8 & 99.5 & 99.8 & 87.0 & 79.3 & &
\end{tabular}

\section{Kappa: $\mathbf{0 . 8 8 8}$}

Exatidão Global: 91.0

Fonte: Dados da Autora.

Tabela 2- Matriz de confusão obtida pelo Maxver com a composição RGB

\begin{tabular}{cccccccc}
\hline Classe & $\mathbf{1}$ & $\mathbf{2}$ & $\mathbf{3}$ & $\mathbf{4}$ & $\mathbf{5}$ & Total & Usuário \\
\hline $\mathbf{1}$ & $\mathbf{3 5 7}$ & 0 & 0 & 5 & 22 & 384 & 93.0 \\
$\mathbf{2}$ & 0 & $\mathbf{3 8 7}$ & 0 & 0 & 0 & 387 & 100.0 \\
$\mathbf{3}$ & 0 & 11 & $\mathbf{4 0 0}$ & 0 & 0 & 411 & 97.3 \\
$\mathbf{4}$ & 5 & 0 & 0 & $\mathbf{3 4 6}$ & 21 & 372 & 93.0 \\
$\mathbf{5}$ & 38 & 2 & 0 & 49 & $\mathbf{3 5 7}$ & 446 & 80.0 \\
Total & 400 & 400 & 400 & 400 & 400 & 2000 & \\
Produtor & 89.2 & 96.8 & 100.0 & 86.5 & 89.2 & & \\
Kappa: 0.904 & & & & & & &
\end{tabular}

Fonte: Dados da Autora. 
Tabela 3 - Matriz de confusão obtida pelo simulador de redes JavaNNS com a composição RGB e o índice NDVI

\begin{tabular}{cccccccc}
\hline Classe & $\mathbf{1}$ & $\mathbf{2}$ & $\mathbf{3}$ & $\mathbf{4}$ & $\mathbf{5}$ & Total & Usuário \\
\hline $\mathbf{1}$ & $\mathbf{1 8 7}$ & 0 & 0 & 3 & 5 & 195 & 95.9 \\
$\mathbf{3}$ & 2 & $\mathbf{1 9 8}$ & 3 & 2 & 0 & 205 & 96.6 \\
$\mathbf{4}$ & 0 & 0 & $\mathbf{1 9 7}$ & 2 & 0 & 199 & 99.0 \\
$\mathbf{5}$ & 3 & 2 & 0 & $\mathbf{1 9 3}$ & 4 & 202 & 95.5 \\
$\mathbf{U}$ & 8 & 0 & 0 & 0 & $\mathbf{1 9 1}$ & 199 & 96.0 \\
Total & 0 & 0 & 0 & 0 & 0 & 0 & 0.0 \\
Produtor & 93.5 & 99.0 & 98.5 & 96.5 & 95.5 & &
\end{tabular}

Kappa: 0.958

Exatidão Global: 96.6

Fonte: Dados da Autora.

Tabela 4 - Matriz de confusão obtida pelo Maxver com a composição RGB e o índice NDVI

\begin{tabular}{cccccccc}
\hline Classe & $\mathbf{1}$ & $\mathbf{2}$ & $\mathbf{3}$ & $\mathbf{4}$ & $\mathbf{5}$ & Total & Usuário \\
\hline $\mathbf{1}$ & $\mathbf{1 8 1}$ & 0 & 0 & 1 & 12 & 194 & 93.5 \\
$\mathbf{3}$ & 0 & $\mathbf{1 9 6}$ & 1 & 0 & 0 & 197 & 99.5 \\
$\mathbf{4}$ & 0 & 3 & $\mathbf{1 9 9}$ & 0 & 0 & 202 & 98.5 \\
$\mathbf{5}$ & 1 & 1 & 0 & $\mathbf{1 7 2}$ & 4 & 178 & 96.6 \\
Total & 18 & 0 & 0 & 27 & $\mathbf{1 8 4}$ & 229 & 80.3 \\
Produtor & 90.5 & 98.0 & 99.5 & 86.0 & 92.0 & &
\end{tabular}

Kappa: 0.915

Exatidão Global: 93.2

Fonte: Dados da Autora. 


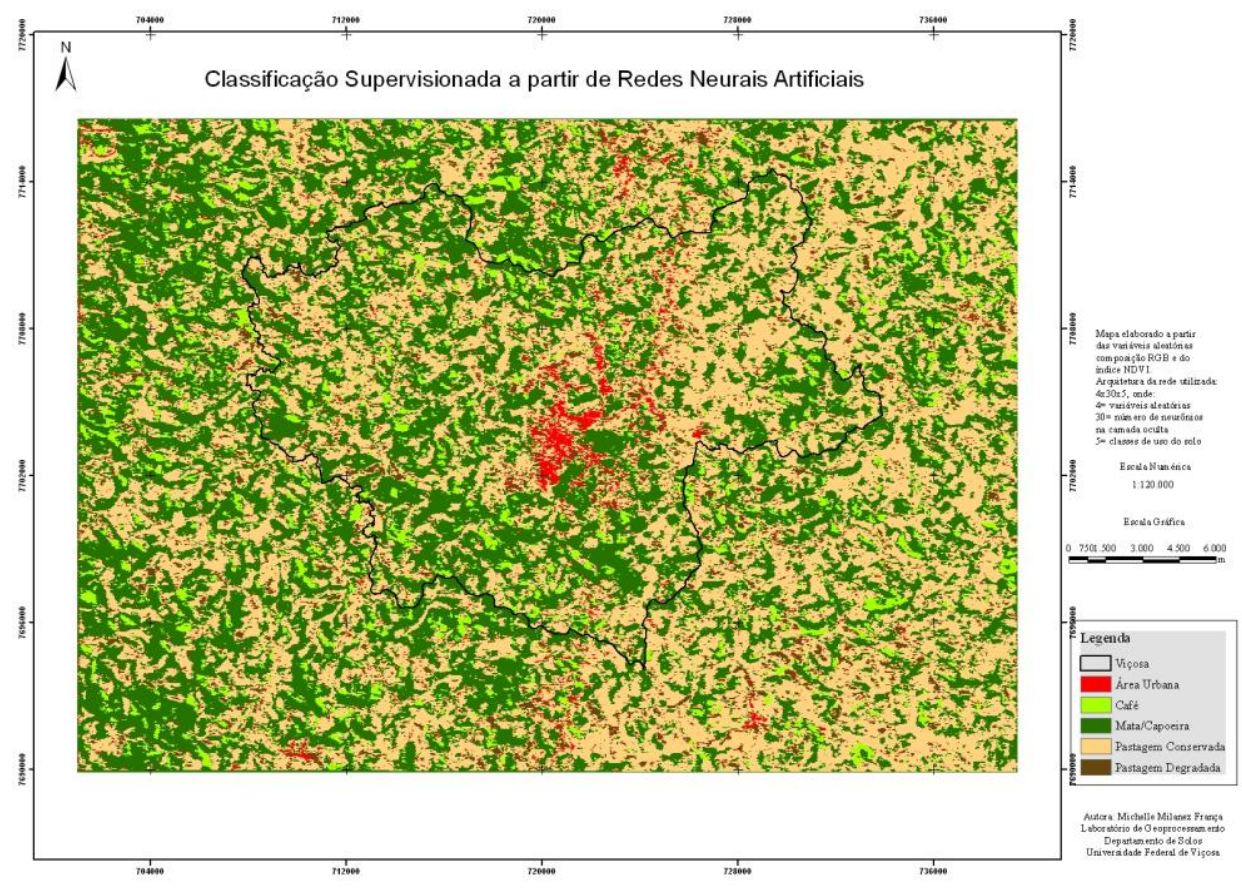

Figura 1 -Cobertura vegetal e uso do solo no município.

Tabela 5 - Distribuição das classes de uso do solo

\begin{tabular}{ccc}
\hline Classe & Área $\left(\mathbf{m}^{\mathbf{2}}\right)$ & Área (ha) \\
\hline Área Urbana & 13311 & 1,3311 \\
Café & 135837 & 13,5837 \\
Mata/Capoeira & 956671 & 95,6671 \\
Pastagem Conservada & 1204276 & 120,4276 \\
Pastagem Degradada & 134905 & 13,4905
\end{tabular}

Fonte: Dados da Autora. 


\section{REFERÊNCIAS BIBLIOGRÁFICAS}

ESRI, 1996. Arcview GIS: The Geographical Information System for everyone. New York: Environmental Systems Research Institute.

FRANÇA, M.M. Avaliação de Classificações Supervisionadas Com Redes Neurais Artificiais MAXVER para Caracterização do Uso da Terra no Município de Viçosa-MG. Monografia em Geografia. Departamento de Artes e Humanidades da Universidade Federal de Viçosa, 2007.

HAYKIN, S. Redes Neurais: princípios e prática. trad. Paulo Martins Engel. $2^{\mathrm{a}}$ ed. Porto Alegre: Bookman, 2001.

JavaNNS. Java Neural Network Simulator. Version 1.1. University of Tübingen.2001

Disponível em:

$<<$ http://www-ra.informatik.uniebingen.de/software/JavaNNSwelcome_e. $\underline{\mathrm{html}>>}$

MATHER, P.M. Computer processing of remote sensed images: an introduction. Chichester: Wiley, 1987.

MOREIRA, M.A. Fundamentos do Sensoriamento Remoto: metodologias de aplicação. $2^{\mathbf{a}}$ ed. Viçosa: UFV, 2003.

NOVO, E.M.L.M. Sensoriamento Remoto: Princípios e Aplicações. São Paulo, Edgard Blucker, 1989.

SCHALKOFF, R.J. Pattern Recognition: Statistical, Structural and Neural Approaches. New York: John Wiley \& Sons, 1992.

VIEIRA, C.A.O. Accuracy of remotley sensing classification of agricultural crops: a comparative study. University of Nottingham, 2000. (Tese de doutorado)

WASSERMAN, P.D. Neural Computing: theory and practice. New York: Van Nostrand Reinhold, 1989. 